\title{
Research on the Performance Evaluation System and Incentive Mechanism of College Counselors
}

\author{
Hou Wei \\ Marxism Institute, Shenyang Jianzhu University \\ Shenyang, China
}

\begin{abstract}
Under the circumstances of college counselors becoming increasingly burned out, this paper puts forward a research on the evaluation system and incentive mechanism for college counselors. This paper constructs the evaluation index system of college counselors from five aspects: evaluation principle screening, evaluation subject setting, evaluation index selection, evaluation system dimension and evaluation method application. Besides, this paper systematically starts with the three aspects of constructing incentive mechanism: principles, contents and methods and ends with the establishment of incentives for college counselors.
\end{abstract}

Keywords - college counselors; performance evaluation system; incentive mechanism

\section{INTRODUCTION}

College counselors are both college teachers and students' "political leaders". The "dual identity" of college counselors plays an important role in promoting college students' academic growth and adapting smoothly to university life. The prerequisite for effective use of the duties of college counselors is to establish a scientific counselor evaluation system, and to achieve an objective evaluation of the performance of college counselors, and to establish appropriate mechanisms.

\section{RESEARCH PROGRESS AT HOME AND ABROAD}

\section{A. Foreign related research}

There are few related studies on the evaluation of teachers' performance in Western countries alone. The results related to performance appraisal are relatively rich, mainly in the following aspects: First, research on appraisal evaluation system. Richard M. Walker and George A. Boyne (2009) pointed out that organizational performance is an important topic in public management research and practice; Monica (2012) believes that performance appraisal system classification from performance results should be divided into: employee behavior, organizational capabilities and performance results and many more. The second is about relevant theoretical research on assessment. Schiffand Hoffman (1996) uses attribution theory to explain how top managers use multi-criteria performance evaluations, how these performance evaluations affect their decision-making processes; Malmi (2001) uses new institutionalism theory to explain why organizations adopt performance evaluation systems And the consequences of these decisions; the third is about the teacher assessment system research. Keith (2006) analyzes teachers and establishes evaluation index system from the perspective of development; Susan E. Lindsay (2002) analyzes teacher performance appraisal from the perspective of feasibility, and puts forward problems and countermeasures.

\section{B. Domestic related research}

In recent years, academic research on the evaluation system of college counselors has focused on the following aspects: First, research on evaluation methods. Zhang Ruijuan (2017) builds a model through fuzzy comprehensive evaluation method to quantitatively assess the performance of counselors, and provides a strong basis for the selection, evaluation and training of counselors; Tang Yexi and Ding Yulan use the FAHP method to ideological and political education of college counselors Conduct objective quantitative evaluation to reduce the randomness and subjective ambiguity in the traditional subjective evaluation process; Huang Qiaoqiu and Liu Jun (2011) started from the goal of performance evaluation of counselors, and selected the integrated method of KPI and 360 degree evaluation to construct college counseling The evaluation system of the staff has designed a practical evaluation element; Chen Chunsheng (2012) has developed a performance evaluation system based on the performance of the multi-evaluation subject with KPI method; the second is the research on the evaluation content. Xu Songwei et al. (2018) comprehensively evaluated the competence of college counselors from four dimensions: business ability, management ability, behavioral ability and personal traits; Zhang Ruijuan (2017) from the perspective of functional departments, teachers and counselors, and students Constructing a scientific and reasonable evaluation index system for college counselors' work performance; Han Feng and $\mathrm{Wu}$ Leiming (2011) extracted key indicators from student evaluation, academic style construction, ideological and political education work, student management work, and employment work to evaluate counselor work The third is about the study of incentive mechanisms. Wang et al. (2018) believe that colleges and universities should start from improving environmental incentives, standardizing assessment mechanisms, optimizing education and training mechanisms, and improving grade promotion mechanisms to stimulate the enthusiasm of college counselors and ease the job burnout of counselors.

\section{Research and analysis at home and abroad}

The existing research still has the following shortcomings: First, in the selection of research perspectives, the academic community usually chooses a certain aspect (quality evaluation, competency evaluation, performance evaluation) to conduct research. The academic community has less research on comprehensive consideration of all aspects of the same 
platform, although it is recommended for colleges and universities. There is a certain similarity between the evaluation of competency and performance evaluation. However, due to different construction objectives, the setting of competency evaluation index has certain limitations compared with performance evaluation. Second, in the construction of the evaluation system, the existing research has problems such as unclear definition of the examination subject, atypical selection of indicators, and narrow application of assessment results. This paper strives to build macro, meso and microscopic three-dimensionality and implement "year-end assessment and quarterly assessment"Two-stage evaluation evaluation system model;Third, the application of the evaluation method, the existing general research methods can not avoid the weight of the subjective judgment (such as the analytic hierarchy process, the Delphi method, the multi-factor comprehensive evaluation method, etc.), even if the weight is bypassed, the assumption or a large number of samples The data is premised, and the requirements for techniques and calculation procedures are high (artificial neural network evaluation method, principal component analysis method, fuzzy comprehensive evaluation method, etc.). This article will avoid the setting weights, and use the fully-arranged polygon comprehensive graphic index method to overcome the above two shortcomings; Third, in the application of evaluation methods, the existing general research methods can not avoid the determination of weights in the subjective judgment (such as the analytic hierarchy process, the Delphi method, the multi-factor comprehensive evaluation method, etc.) Even if the weight is bypassed, it is premised on the assumption or a large amount of sample data, and at the same time requires high technical and operational procedures (artificial neural network evaluation method, principal component analysis method, fuzzy comprehensive evaluation method, etc.). This topic will avoid the setting weights, and use the fully-arranged polygon comprehensive graphic index method to overcome the above two shortcomings. Fourth, the construction of the work incentive mechanism, the current college counselor work incentive mechanism is more one-sided, unitary, lack of practice-based systemic arrangements, this paper combined with the current college counselors to perform the corresponding characteristics of the overall proposed corresponding mechanism.

\section{THE CONSTRUCTION OF COLLEGE COUNSELORS PERFORMANCE EVALUATION SYSTEM}

\section{A. Evaluation principle}

(1) Principle of relevance. The attribute of "double function" of college counselors determines that college counselors should accept supervision from different subjects when they face different functions of different student groups. Some departments have a low degree of relevance to the functions of college counselors, and the supervision role is small. Some departments have a high degree of relevance to the functions of college counselors, and the supervision role is great. In order to ensure the scientificity of the evaluation and the evaluation results are highly time-sensitive, when determining the evaluation subject, the principle of relevance should be adhered to, and the evaluation subject with low relevance should be removed to ensure that the highly relevant evaluation subject truly evaluates effect [1].

(2) Intuitive and measurable principle. The evaluation system can effectively play the evaluation function, provided that the indicators can be described in quantifiable language to achieve quantifiable definition of each indicator. It is the purpose of constructing the evaluation system of college counselors by determining the quantifiable results through the evaluation system to determine the ability of college counselors to perform their duties. In order to ensure the quantifiable final result, it is necessary to ensure that the indicators can be quantified, and the indicators can be accurately digitized by conversion to form scientific evaluation data. This requires adhering to the principle of visual measurability and ensuring evaluation. The indicators are intuitive and testable.

(3) The principle of being small and fine. The operation is simple and convenient, and the obtained evaluation data is more scientific. It is an important goal of constructing the evaluation system of college counselors. This requires the principle of "small and precise" in the determination of the evaluation subject and the selection of evaluation indicators. The questionnaires, face-to-face interviews and expert consultations are used to eliminate the relatively low-level evaluation subjects and evaluation indicators, and establish a strict structure. A highly operational evaluation system.

\section{B. Evaluation subjects and indicators}

College counselors are different from ordinary teachers and general administrative staff. The functions of college counselors determine that college counselors have both the status of teachers and the status of administrative cadres. They must accept the assessment of their colleges and accept the competent student departments Departmental supervision. At the same time, whether college counselors can effectively perform their functions depends to a certain extent on the teamwork ability of college counselors. According to the nature of the work of college counselors and the competent departments of management and supervision, the subject of evaluation of college counselors can be divided into four parts: the party committee student work department, the colleges and universities (department) party and government organizations, college students, and colleagues. In the system design, the "Professional Competency Standards for Higher School Counselors" promulgated by the Ministry of Education in 2017 shall prevail, insisting on the functional department as the macro dimension, the party and government organizations and colleagues in the department as the middle dimension, and the student subject as the micro dimension. Conduct an assessment and implement a model of the evaluation and evaluation system that combines the two phases of "year-end assessment and quarterly assessment".

(1) Party Committee Student Work Department. College counselors are the main managers and planners of students' study and life. The ability of college counselors to perform their duties and work results must be subject to the leadership and supervision of the party committee student work department [2]. According to the party committee student work department, the leading staff of college counselors The division 
of responsibilities, the party committee student work department mainly focuses on the evaluation of college counselors' student management ability and the sense of service for students. Specific assessment indicators include professional literacy, job performance, work ability, work attitude, and growth and development.

(2) Party and government organizations in colleges and universities. The "dual function" of college counselors determines that college counselors should also play the ideological and political education function while undertaking the daily management of students. The college counselors' work on students' ideological and political education is not only reflected in the classroom, but also in the daily management work. The investigation of the ideological and political education work of college counselors is mainly carried out by the party and government organizations of the colleges and universities where the college students are located. Therefore, the party and government organizations of colleges and universities are important subjects of evaluation. Specific assessment indicators include professional ethics, work attitude, capacity building, and work innovation.

(3) College students. College counselors work for college students. Whether college students are satisfied and can accept the leadership of college counselors directly determines the work ability and work effect of college counselors. Therefore, college students are important subjects for college counselors to perform their duties. Specific assessment indicators include professional ethics, ideological education, daily affairs management, crisis response, academic guidance, career planning and employment guidance, mental health education and counseling.

(4) Colleagues. The counselor's colleague is the collaborator of the counselor's work and the bystander of the counselor's work. On the one hand, the colleague as the evaluation subject can give the counselor a fair evaluation from the perspective of the bystander, on the other hand, it can be more scientifically quantified. Out of college counselors teamwork ability indicators. Specific assessment indicators include professional ethics, work quality, and work spirit.

\section{Evaluation method}

Aiming at the insurmountable influence of the traditional evaluation system on the subjective judgment and the premise of assuming or a large number of sample data, the technical and operational procedures require high weakness. This paper mainly uses the fully-arranged polygon comprehensive graphic index method to the college counselors. Evaluation of the job status. Avoiding the subjective judgment of experts to determine the weight, the implementation of the calculation method is simple and operability.

\section{ESTABLISH A COLLEGE COUNSELOR'S PERFORMANCE INCENTIVE MECHANISM}

In view of the fact that there are few incentive measures, single form, and ineffective effects in the incentive mechanism of college counselors, the incentive mechanism of college counselors should be constructed from the principles, contents and methods of constructing incentive mechanism.

\section{A. Build an incentive principle that meets the needs of college counselors for career development}

Formulating scientific and reasonable incentive principles is the direction and goal of promoting the career development of college counselors [3]. Measuring whether the incentive principle is scientific and reasonable, should it be based on whether it can stimulate the enthusiasm of college counselors to perform their duties. This requires that we should not simply adopt a one-size-fits-all approach in the process of formulating incentive principles. We must formulate flexible and diverse incentive mechanisms based on the different characteristics of different universities and the different needs of counselors at different stages of employment.

\section{B. Design the motivational content of the trinity of material, spiritual and political interests}

The key factor in whether the incentive mechanism can play a role is whether the college counselors value the results obtained through hard work. In the current era, with the rapid development of the material level, people tend to transcend the material level in pursuit and pay more attention to the satisfaction of the spiritual level. Therefore, in designing the incentive content, we must overcome the previous emphasis on material interests and will benefit from material interests and spirits. In terms of interests and political interests, the content of the incentive mechanism for college counselors is set.

\section{Choose an incentive method that suits the characteristics of each university}

According to the incentive content, the incentive method is determined, and the incentive method is determined mainly from the aspects of material, spiritual and evaluation. Different universities choose their own focus for their own characteristics. For example, college counselors with high performance and high performance evaluation can not only give monetary rewards, but also create a good working environment; in addition to giving recognition and public praise in terms of spiritual interests In addition, it is also possible to start from the honor and give one-on-one guidance and other aspects; in terms of political interests, it can be rewarded in many aspects from the promotion of positions and the role of leadership.

\section{CONCLUSION}

The evaluation system of counselors' performance in the existing colleges has not yet reached the organic connection with the goal of training talents in schools. The work of a few counselors is one-sided and utilitarian. This paper selects the perspective of performance evaluation, and starts from different evaluation subjects, using the fully-arranged polygon comprehensive graphic index method to construct the college counselor evaluation system, which not only further stimulates the intrinsic motivation of the counselors, but also promotes the counselor to realize the school education management. The organic unity of the concept and the talent training goal, and can promote the counselor to face the students with a more positive work attitude, strive to improve the work ability and business quality, and promote the all-round development of students. 


\section{ACKNOWLEDGMENT}

Sources of the project:

1. Liaoning Province Graduate Student Enrollment Quality Project: Research on Graduate Student Enrollment Quality Evaluation and Guarantee Mechanism (YZ2018YB035).

2. Liaoning Social Science Planning Fund Project: University Counselor Performance Evaluation System and Incentive Mechanism Research (L18BSZ013).

About the Author:

Hou Wei (1980-), female, associate professor of Shenyang Jianzhu University, postdoctoral, master tutor, engaged in ideological and political education research.

Contact: Marxism Institute, Shenyang Jianzhu University, No. 9 Weinan East Road, Hunnan New District, Shenyang, China Postcode: 110168.

\section{REFERENCES}

[1] Peng Yu. The performance evaluation and incentive mechanism construction of college counselors from the perspective of dual identity [J]. Ideological and theoretical education guide 2017 (12).

[2] Xu Songwei, Liu Bingyong. Research on the Evaluation Index System of College Counselors' Competency-Based on the Survey of 12 Key Universities in China[J]. College Counselor 2018(10).

[3] Zhang Ruijuan. Research on the Performance Evaluation of College Counselors[J]. Journal of Inner Mongolia University of Finance and Economics 2017(6) 